\title{
Frontotemporal dementia: impact of P301 L tau mutation on a healthy carrier
}

\author{
A Alberici, C Gobbo, A Panzacchi, F Nicosia, R Ghidoni, L Benussi, C Hock, A Papassotiropoulos, \\ P Liberini, J H Growdon, G B Frisoni, A Villa, O Zanetti, S Cappa, F Fazio, G Binetti
}

J Neurol Neurosurg Psychiatry 2004;75:1607-1610. doi: 10.1136/innp.2003.021295

Frontotemporal dementia (FTD) is the second commonest form of dementia after Alzheimer's disease, but its clinical and biological features are less well known. To uncover its earliest signs, we studied the main clinical, neuroimaging, and biochemical findings in an asymptomatic carrier from a three generation FTD family, bearing the P301L pathogenic mutation in the tau gene. Except for selective impairment on the Verbal Fluency Test for letters, all cognitive tests were normal. The brain computed tomography scan was normal, but the brain single photon emission computed tomography and statistical parametric mapping (SPECT-SPM) scan revealed bilateral frontal lobe hypoperfusion. Levels of total tau, 181P-tau, and A $\beta 1-42$ in the cerebrospinal fluid were increased compared with control values. We conclude that detection of these distinctive abnormalities should improve early diagnostic accuracy for FTD and help distinguish it from Alzheimer's disease.

$\mathrm{F}$ rontotemporal dementia (FTD) is considered to be the second commonest neurodegenerative disorder to cause dementia after Alzheimer's disease (AD). ${ }^{1}$ The clinical spectrum of FTD includes prominent behavioural disturbances, impairment in language, and poor executive functions. In some instances, FTD is associated with parkinsonism, whereas in other cases it occurs concomitantly with motor neurone disease. ${ }^{2-5}$ Regardless of onset, FTD progresses to disabling dementia. ${ }^{6}$ It usually occurs as a sporadic disease, but familial cases, (FFTD) mainly due to mutations in the tau gene, are common. ${ }^{7-13}$

The study of presymptomatic individuals who carry a pathogenic FTD mutation may help in elucidating the natural history of the disease. Here, we provide a detailed clinical description of an asymptomatic carrier from a three generation FTD family with a pathogenic mutation P301L in the tau gene.

\section{METHODS}

\section{Clinical and cognitive examination}

We personally examined patient III;7 and his siblings III;8, III;9, and III;10 (fig 1A). They all underwent extensive clinical and neurological examinations, including neuroimaging investigations and a detailed cognitive assessment, as previously reported. ${ }^{14-16}$ In addition, we reviewed the medical records of all affected individuals in the family to reconstruct the main clinical features of the disease.

\section{Mutation analyses}

Blood samples for DNA were taken from III;6, III;7, III;8, III;9, and III; 10 after informed consent was obtained. All exons of the tau gene were sequenced and $A P O E$ was genotyped as previously described..$^{13}$

\section{Single photon emission computed tomography and statistical parametric mapping (SPECT-SPM)}

SPECT imaging of cerebral blood flow for the subjects III; 10 and III;8 and for 21 control subjects ( 11 men, 10 women; mean age (SD) 51 (16) years) was performed using a maximum dose of $740 \mathrm{MBq}{ }^{99 \mathrm{~m}}$ Tc-ethyl cysteinate dimer (ECD), injected intravenously with the subjects supine in a resting state with eyes closed. Thirty minutes after the injection of the tracer, brain SPECT was performed using a triple-head SPECT system (PRISM 3000 Picker International, $\mathrm{OH})$ with higher resolution fan beam collimators. For each camera, projection data were obtained in a $128 \times 128$ format for 24 angles of $120^{\circ}$ at 40 seconds per angle. A Hanning filter (cut-off $=0.5$ cycle $/ \mathrm{cm}$ ) was used for SPECT image reconstruction. Attenuation correction was performed using Chang's method. The data were analysed with statistical parametric mapping (SPM99) (using software from the Wellcome Department of Cognitive Neurology, London, UK) implemented in Matlab 4.2 (Math-works Inc, Sherborn, MA, USA), running on a SUN Sparc Station 20. The subjects' scans were fit into a standard stereotactic space. ${ }^{17}$

Validation of statistical parametric mapping (SPM) for assessment of functional cerebral changes with SPECT was reported in a simulation study ${ }^{18}$ and in a clinical study. ${ }^{19}$

\section{Cerebrospinal fluid measurements}

After obtaining written consent, we collected cerebrospinal fluid (CSF) samples from subject III;10, two patients with sporadic $\mathrm{AD}$ and three age matched healthy control (HC) subjects. Levels of A $\beta 1-42$ and tau protein in the CSF were determined by enzyme linked immunosorbent assay (Innogenetics, Belgium). CSF tau phosphorylated at threonine 181 was quantified using a prototype version of the INNOTEST phospho-tau (181P-tau) as described elsewhere. ${ }^{20}$

\section{RESULTS}

Genealogical investigation and patient description Information about the family is summarised in fig lA.

Patient III; 7 was the index case of this family; at 50 years he had alien limb syndrome with associated extrapyramidal signs, initially diagnosed as corticobasal degeneration. Follow up evaluations documented rapid progression of the disease into overt FTD; he died after eight years of the illness. Enquiry into his family history revealed that six other family

Abbreviations: AD, Alzheimer's disease; CSF, cerebrospinal fluid; FTD, frontotemporal dementia; HC, healthy controls; SPECT-SPM, single photon emission computed tomography and statistical parametric mapping 
A Main clinical features of family members

Family pedigree

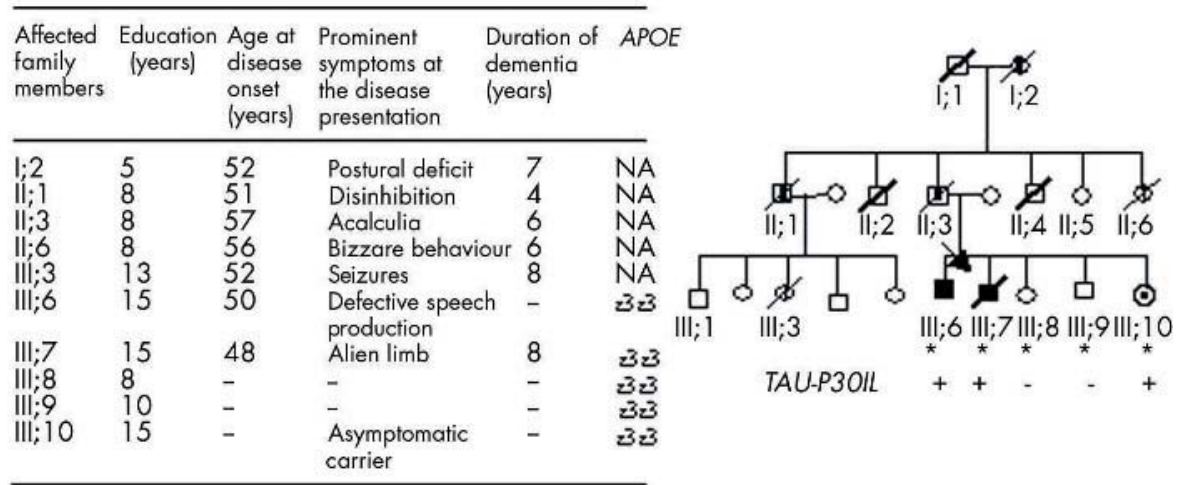

B SPECT-SPM Analysis of subject III; 10
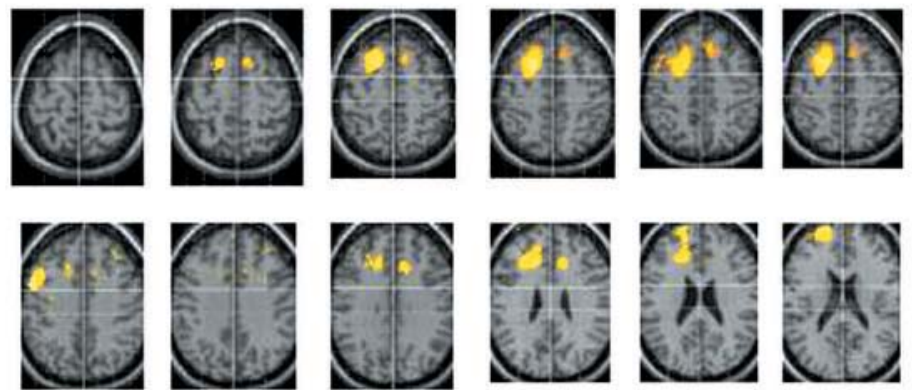

T value
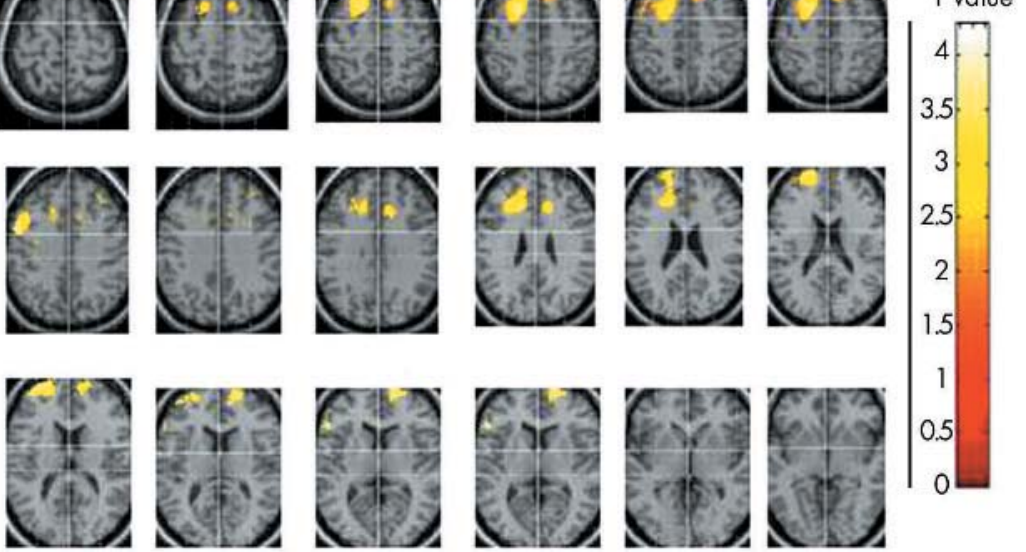

Figure 1 (A) Men are represented by $\square$; women $\bigcirc$; deceased individuals $\square$; affected individuals $\mathbf{\square}$; considered affected on the basis of clinical records - T; asymptomatic carrier $\odot$; DNA examined *; NA, not available; Tau-P301L (+): associated with tau mutation in P301L in exon ten. (B) SPECT-SPM analysis: subject III;10. Significant reduction of blood flow in frontal areas (in yellow) are superimposed on T1-NMR axial image standard brain rendering. (Statistical threshold, $\mathrm{p}<0.001$ ).

members over three generations had had neurological disorders ranging from psychiatric disturbances to motor deficits and dementia.

Subjects III;8 and III;9 were examined at the age of 58 years and 52 years, respectively, and their neurological and cognitive examinations, and neuroimaging investigations were normal. Subject III; 10, at the age of 50 years, had a normal neurological examination, with no extrapyramidal deficit or frontal release sign. She was leading an appropriate social life, and she and her relatives had no complaints about behavioural disturbances or mood disorders. She was able to satisfy the requirements of her very demanding job, as she had been doing. On cognitive evaluation, her scores were normal on all tests, except for a reduction on the Verbal Fluency Test for letters. A total of 17 words were produced in one minute, compared with 30 and 34 by her two siblings (table 1). Her brain computed tomography (CT) scans were normal (data not shown).

\section{Mutation analysis}

Genetic analyses revealed an amino acid substitution $\mathrm{P} \rightarrow \mathrm{L}$ at position 301 of exon 10 of the tau gene in the asymptomatic individual III;10. The same mutation was present in the index case III; 7 and in the affected sibling III;6; no mutations were found in the healthy siblings III;8 and III;9. APOE genotype is given in fig lA.

\section{SPECT-SPM}

In Subject III;10, SPECT abnormalities were not visible at gross inspection (data not shown). SPECT-SPM (fig 1B) analysis showed that significant reductions of cerebral blood flow were evident in the frontal lobes $(p<0.001)$. These involved in particular the dorsolateral frontal cortex and the frontal poles, and the mesial frontal cortex. In subject III;8, SPECT-SPM was within normal range as compared with age matched controls.

\section{CSF determinations}

CSF A $\beta 1-42$ levels of subject III; 10 (1101 pg/ml) were higher than those of patients with sporadic $\mathrm{AD}(42 \mathrm{l} ; 412 \mathrm{pg} / \mathrm{ml})$ and HC $(658-924 \mathrm{pg} / \mathrm{ml})$, and normative (SD) data (794 (218) $\mathrm{pg} / \mathrm{ml}){ }^{21}$ In the same subject, the levels of CSF tau protein $(303 \mathrm{pg} / \mathrm{ml})$ and $181 \mathrm{P}$-tau $(45 \mathrm{pg} / \mathrm{ml})$ were lower than those of the patients with $\mathrm{AD}$ (total tau 727; $562 \mathrm{pg} / \mathrm{ml}$; 181P-tau 92; $69 \mathrm{pg} / \mathrm{ml}$ ) and higher than those of HC (total tau $154-178 \mathrm{pg} / \mathrm{ml} ; 181 \mathrm{P}-\mathrm{tau} 32-38 \mathrm{pg} / \mathrm{ml}$ ), and normative data (total tau $136(89) \mathrm{pg} / \mathrm{ml}) .^{22}$

\section{DISCUSSION}

We have documented distinctive regional brain dysfunction and biochemical pathological changes that precede onset of dementia in an asymptomatic carrier from a family with FTD caused by the P301L mutation in the tau gene. Subject III;10 


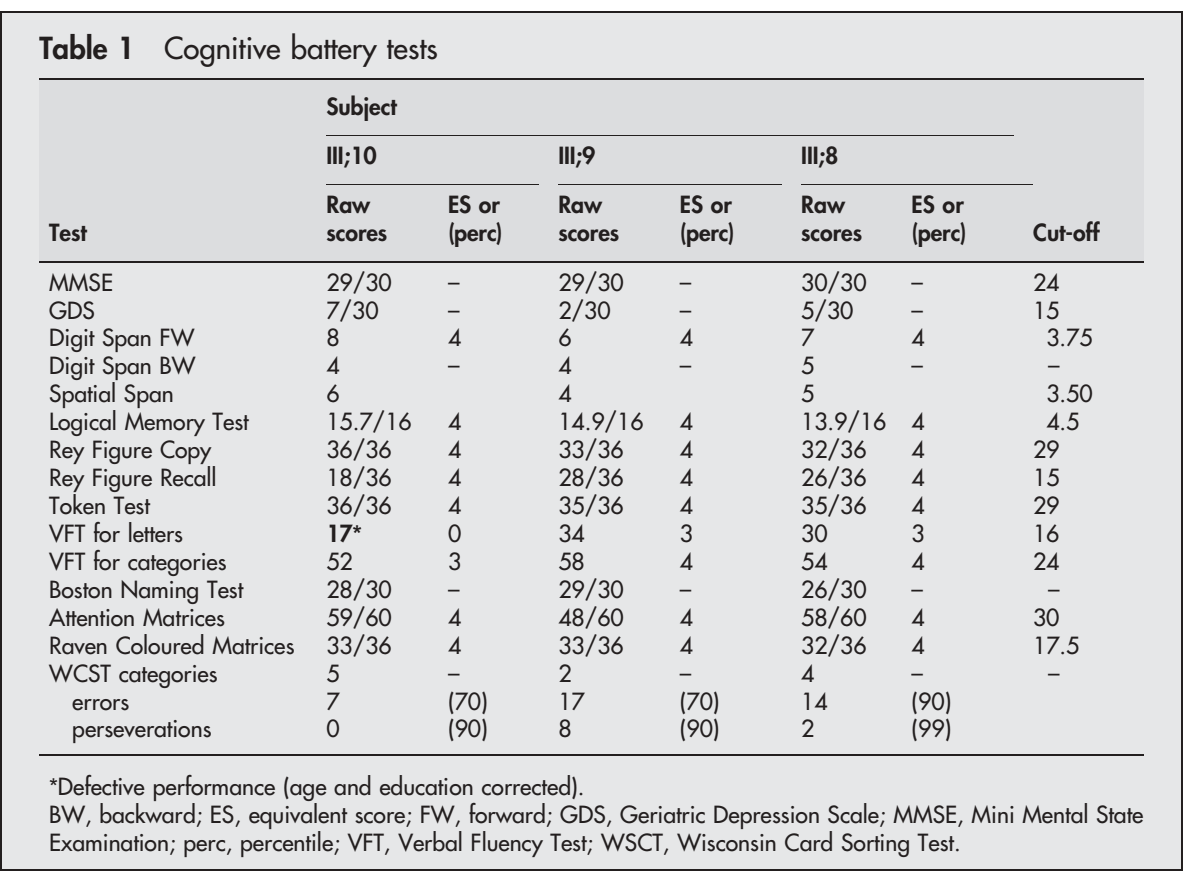

was 50 years old when first examined and just entering the decade when most of her family members developed the neurological symptoms. Two of her siblings had $\mathrm{P} \rightarrow \mathrm{L}$ mutation and overt neurological signs consistent with FTD; two other siblings did not have the mutation and were neurologically normal. When first seen, the sole deficit on formal cognitive testing in subject III;10 was the Verbal Fluency Test for letters. Language capacities are impaired very early on in the course of sporadic $\mathrm{FTD}^{22}$ and the presence of a deficit in verbal fluency in our subject underscores the primacy of language disturbances in the evolution of FTD. Previous studies have demonstrated that presymptomatic P301L mutation carriers not only have impaired verbal fluency but also frontal executive functions. ${ }^{23}$ Early diagnosis of FTD may be aided by an extensive assessment of language domains, in addition to executive functions.

Conventional brain CT scans did not show any morphological change in our asymptomatic subject, but a SPECT-SPM scan detected diminished blood flow in the frontal cortical regions. This evidence of frontal lobe dysfunction on physiologic neuroimaging is consistent with the cognitive deficit on the Verbal Fluency Test and in agreement with previous reports. ${ }^{24}$

The silent neurodegenerative process detected by SPECTSPM was associated with biochemical alterations of proteins in the CSF-that is, increased levels of A $\beta 1-42$, total tau, and 181P-tau. Although it is somewhat surprising to find increased levels of tau in an asymptomatic person, this finding is expected in established $\mathrm{AD}$, and is controversial in patients with FTD. ${ }^{25-27}$ The CSF formula in subject III; 10 is remarkably different from that associated with $\mathrm{AD}$ patients in whom increased levels of tau are accompanied by decreased levels of $\mathrm{A} \beta 1-42$, and it also differs from the normal controls. In FTD, amyloid processing is influenced by age and $A P O E \in 4$ allele $^{28}$; in subject III;10, we can argue that future plaque deposition of excessive $A \beta 1-42$ could be an event only related to ageing and not to the APOE genotype, because the $\epsilon 4$ allele is not present. Based on the CSF results, increased levels of CSF A $\beta 1-42$, total tau, and 181P-tau levels might be considered early preclinical events in subject III; 10 . The time interval between the biochemical changes and overt clinical signs remains unknown, although considering the amyloid deposits in the $\mathrm{AD}$ brain, it could be years. The specific 181P-tau species might be even more informative in tracking the disease progression. In overt FTD patients, 181Ptau in CSF is almost undetectable, ${ }^{20}$ as tau might be first solubilised, then abnormally phosphorylated and eventually sequestered in tangle formation. ${ }^{29}$ Further longitudinal evaluation of these biological and imaging parameters may contribute to the establishment of an index of phenoconversion to follow the effects mediated by the mutation and leading to dementia.

\section{ACKNOWLEDGEMENTS}

The authors wish to acknowledge the helpful and generous collaboration of the members of the family, which was essential for this study.

We are grateful to Prof Daniela Perani for her scientific contribution. Mrs Eileen Johnston is acknowledged for her helpful editing.

\section{Authors' affiliations}

A Alberici, F Nicosia, R Ghidoni, L Benussi, A Villa, G Binetti, Neurobiology Lab, IRCCS S. Giovanni di Dio-FBF, Brescia, Italy C Gobbo, A Panzacchi, S Cappa, F Fazio, Department of Nuclear Medicine, Institute H S Raffaele, Milan, Italy

C Hock, A Papassotiropoulos, Department of Psychiatric Research, University of Zurich, Zurich, Switzerland

P Liberini, Department of Neurology, Spedali Civili, Brescia, Italy J H Growdon, Department of Neurology, Massachusetts General Hospital, Boston, MA, USA

G B Frisoni, Epidemiology and Neuroimaging Lab, IRCCS S. Giovanni di Dio-FBF, Brescia, Italy

O Zanetti, Alzheimer Research Unit, IRCCS S Giovanni di Dio-FBF, Brescia, Italy

F Fazio, INB-CNR University of Milan-Bicocca, Milan, Italy

G Binetti, Memory Clinic, IRCCS S. Giovanni di Dio-FBF, Brescia, Italy

This work was supported by grant no. ICS030.13/RF97.46 from the Ministero della Salute, Italy.

Competing interests: none declared

Correspondence to: Dr G Binetti, Memory Clinic, IRCCS S. Giovanni di Dio-FBF, Via Pilastroni 4, 25123 Brescia, Italy; gbinetti@oh-fbf.it

Received 23 June 2003

In revised form 23 January 2004

Accepted 26 January 2004 


\section{REFERENCES}

1 Snowden JS, Neary D, Mann DM. Frontotemporal dementia. Br J Psychiatry 2002; 180:140-3.

2 The Lund and Manchester Groups. Clinical and neuropathological criteria for frontotemporal dementia. J Neurol Neurosurg Psychiatry 1994;57:416-18.

3 Neary D, Snowden JS, Gustafson L, et al. Frontotemporal lobar degeneration-a consensus on clinical diagnostic criteria. Neurology 1998:51:1546-54.

4 McKhann GM, Albert MS, Grossman M, et al. Clinical and pathological diagnosis of frontotemporal dementia. Arch Neurol 2001;58:1803-9.

5 Morris HR, Khan MN, Janssen JC, et al. The genetic and pathological classification of familial frontotemporal dementia. Arch Neurol 2001;58:1813-16.

6 Binetti G, Locascio JJ, Corkin S, et al. Differences between Pick disease and Alzheimer disease in clinical appearance and rate of cognitive decline. Arch Neurol 2000;57:225-32

7 Stevens $M$, van Duijn $C M$, Kamphorst W, et al. Familial aggregation in frontotemporal dementia. Neurology 1998;50:1541-545.

8 Hutton M, Lendon C, Rizzu P, et al. Association of missense and 5'-splice-site mutations in tau with inherited dementia FTDP-17. Nature 1998:393:702-5.

9 Dumanchin C, Camuzat A, Campion D, et al. Segregation of a missense mutation in the microtubule-associated protein tau gene with familial frontotemporal dementia and parkinsonism. Hum Mol Genet 1998;11:1825-9.

10 Houlden H, Baker M, Adamson J, et al. Frequency of tau mutations in three series of non-Alzheimer's degenerative dementia. Ann Neurol 1999;46:243-8.

11 Rizzu $\mathbf{P}$, van Swieten JC, Joosse $M$, et al. High prevalence of mutations in the microtubule-associated protein tau in a population study of frontotemporal dementia in the Netherlands. Am J Hum Genet 1999;64:414-21.

12 Poorkaj P, Grossman M, Steinbart E, et al. Frequency of tau gene mutations in familial and sporadic cases of non-alzheimer dementia. Arch Neurol 2001:58:383-7.

13 Binetti G, Nicosia F, Benussi L, et al. Prevalence of TAU mutations in an Italian clinical series of familial frontotemporal patients. Neurosci Lett 2003;338:85-7.

14 Binetti G, Magni E, Padovani A, et al. Executive dysfunction in early Alzheimer's disease. J Neurol Neurosurg Psychiatry 1996;60:91-3.

15 Caffarra P, Vezzadini G, Dieci F, et al. Rey-Osterrieth complex figure: normative values in an Italian population sample. Neurol Sci 2002;22:443-7.
16 Heaton RK, Chelune GJ, Talley JK, et al. Wisconsin Card Sorting Test, Forma completa revisionata, adattamento italiano a cura di Hardoy MC, Carta MG, Hardoy MJ e Cabras PL, Organizzazioni Speciali, Firenze, 2000:101-8.

17 Talairach J, Tournoux P. Co-planar stereotaxic atlas of the human brain Stuttgart/New York: Georg Thieme Verlag, 1988.

18 Stamatakis EA, Glabus MF, Wyper DJ, et al. Validation of statistical parametric mapping (SPM) in assessing cerebral lesions: a simulation study. Neuroimage 1999;10:397-407.

19 Barnes A, Lusman D, Patterson J, et al. The use of statistical parametric mapping (SPM96) as a decision aid in the differential diagnosis of dementia using 99mTc-HMPAO SPECT. Behav Neurol 2000;12:77-86.

20 Vanmechelen E, Vanderstichele H, Davidsson P, et al. Quantification of tau phosphorylated at threonine 181 in human cerebrospinal fluid: a sandwich ELISA with a synthetic phosphopeptide for standardization. Neurosc Lett 2000;285:49-52.

21 Sjogren $M$, Vanderstichele $H$, Agren $H$, et al. Tau and $A \beta 42$ in cerebrospinal fluid from healthy adults 21-93 years of age: establishment of reference values. Clin Chem 2001;47:1776-81

22 Siri S, Benaglio I, Frigerio A, et al. A brief neuropsychological assessment for the differential diagnosis between frontotemporal dementia and Alzheimer's disease. Eur J Neurol 2001;8:125-32.

23 Geschwind DH, Robidoux J, Alarcon M, et al. Dementia and neurodevelopmental predisposition: cognitive dysfunction in presymptomatic subjects precedes dementia by decades in frontotemporal dementia. Ann Neurol 2001;50:741-6.

24 Kelley WM, Miezin FM, McDermott KB, et al. Hemispheric specialization in human dorsal frontal cortex and medial temporal lobe for verbal and non verbal memory encoding. Neuron 1998;20:927-36.

25 Siogren M, Minthon L, Davidsson P, et al. CSF levels of tau, $\beta$-amyloid ${ }_{1-42}$ and GAP-43 in frontotemporal dementia, other types of dementia and normal aging. J Neural Transm 2000;107:563-79.

26 Riemenschneider $M$, Wagenpfeil S, Diehl J, et al. Tau and Abeta42 protein in CSF of patients with frontotemporal degeneration. Neurology 2002;58:1585-6.

27 Golde TE, Eckman CB, Younkin SG. Biochemical detection of Abeta isoforms: implications for pathogenesis, diagnosis, and treatment of Alzheimer's disease. Biochim Biophys Acta 2000;1502:172-87.

28 Mann DMA, McDonagh AM, Pickering-Brown SM et al. Amyloid $\beta$ protein deposition in patients with frontotemporal lobar degeneration: relationship to age and apolipoprotein E genotype. Neurosci Lett 2001;304:161-4.

29 Lee VM, Goedert M, Trojanowski JQ. Neurodegenerative tauopathies. Annu Rev Neurosci 2001;24:121-59. 